\title{
Metallic Pins as Electrodes in Low-Cost (Bio)Electroanalytical Devices ${ }^{\dagger}$
}

\author{
Andrea González-López, Olaya Amor-Gutiérrez, Estefanía Costa-Rama and \\ M. Teresa Fernández-Abedul *
}

Department of Physical and Analytical Chemistry, University of Oviedo, Av. Julián Clavería 8, 33006 Oviedo, Spain; agl.andreaglez@gmail.com (A.G.-L.); olayamor23@gmail.com (O.A.-G.); costaestefania@uniovi.es (E.C.R.)

* Correspondence: mtfernandeza@uniovi.es

+ Presented at the 1st International Electronic Conference on Biosensors, 2-17 November 2020; Available online: https://iecb2020.sciforum.net/

Received: date; Accepted: date; Published: date

\begin{abstract}
The increasing demand of fast and on-site information has grown the interest in developing simple and portable analytical devices that provide reliable responses. Electroanalytical devices fit perfectly with these purposes because of their ease-of-use, low-cost and facility of miniaturization. Moreover, the growing interest in the construction of do-it-yourself electronic devices has spread the use of common and mass-produced materials for the development of analytical devices. In this context, the use of gold-plated pins from standard connections and stainless-steel pins from needlework as electrodes in (bio)electroanalytical platforms is presented here. Three different analytical platforms combining those pins with paper, transparency sheets or micropipette tips were constructed and applied in food and environmental analysis: glucose determination in beverages and surfactant analysis in water.
\end{abstract}

Keywords: electrochemical sensor; electroanalytical device; paper-based analytical device; pinbased electrodes; micropipette-tip electrochemical cell; enzymatic sensor; glucose; water analysis; sodium dodecyl sulfate

\section{Introduction}

Important current trends in Analytical chemistry such as simplicity, miniaturization, reduction of costs and portability have led to explore the use of common mass-produced materials for the construction of analytical devices. The use of these materials (e.g., paper [1-5], sewing pins [6-9], office transparency sheets [7,10], thread [11], etc.) provides cheap, highly versatile and, above all, easily available devices. Many of them, especially those based on paper, are based on a colorimetric detection being cheap and easy-to-use and avoiding the use of instrumentation; however, they can only give (semi)quantitative information. Electrochemical detection is a good alternative due to its sensitivity and accuracy as well as its ability for miniaturization. Moreover, it does not require high amount of reagents or sample, neither complex instrumentation.

Taking this into account, here it is briefly described the construction of three different platforms based on paper and/or on pin electrodes. In the first example, gold-plated pins from a standard commercial connection act as reference (RE) and counter (CE) electrodes that were combined with a paper-based working electrode (WE) $[12,13]$. This platform showed good analytical features and it was used for developing an enzymatic glucose sensor. The good performance of electrodes based on stainless-steel pins was also demonstrated constructing an enzymatic glucose sensor in which a transparency sheet was used as substrate and the pin acting as WE was modified with carbon ink [7]. 
In a different and last design, the high versatility of the pins allowed to insert them in a micropipette tip to obtain a system able to take the sample and perform electrochemical measurements in the same tip [14]. This device was used for determining anionic surfactants using methylene blue as indicator.

\section{Materials and Methods}

\subsection{Chemicals, Materials and Apparatus}

For the construction of the electrochemical devices the following reagents and materials were employed: N,N-dimethylformamide (DMF), carbon paste, Whatman ${ }^{\mathrm{TM}}$ paper grade 1, gold-plated connector headers, stainless-steel pins, 100-1000 $\mu \mathrm{L}$ polypropylene micropipette tips, transparency sheets (cut in $3 \times 2 \mathrm{~cm}$ approximately). A wax printer was used to delimit hydrophobic areas by wax printing the paper.

As analytes, glucose and sodium dodecyl sulfate (SDS) were used. Other important reagents were glucose oxidase (GOx), horseradish peroxidase (HRP), potassium ferrocyanide, methylene blue (MB) and chloroform. Working solutions of glucose, GOx, HRP and potassium ferrocyanide were prepared in $0.1 \mathrm{M}$ Tris- $\mathrm{HNO}_{3} \mathrm{pH}$ 7.2; working solutions of SDS were prepared in water and working solutions of $\mathrm{MB}$ were prepared in $0.5 \mathrm{M} \mathrm{HCl}$.

For the electrochemical measurements, an Autolab potentiostat controlled by Nova 2.1.2 software was used. A 3-pin Dupont cable or an edge connector was used as interface to connect the devices with the potentiostat.

\subsection{Construction of the Paper-Based Electrochemical Cell}

The paper-based working electrodes were fabricated as follows [12,13]: a circle pattern was waxprinted on the Whatman ${ }^{\mathrm{TM}}$ paper; then, the wax was diffused at $100^{\circ} \mathrm{C}$ on a heating plate for 1 min and $2 \mu \mathrm{L}$ of a carbon ink (23\% of carbon paste in DMF) was deposited on the hydrophilic area limited by the wax. After $12 \mathrm{~h}$ during which the carbon ink dried completely, the piece of paper containing this working electrode (WE) was placed between the pins of the connector header as indicated in Figure 1A. In this way, those pins act as reference (RE) and counter (CE) electrode and also, as connection for the WE.

To perform electrochemical measurements with this device, $10 \mu \mathrm{L}$ of working solution was deposited covering the three electrodes.

\subsection{Construction of the Pin-Based Electrochemical Cell}

For the construction of the pin-based device [7], the pins were previously cleaned by sonication in isopropyl alcohol and then, those used as WE were modified with carbon ink (50\% carbon paste in DMF). The procedure for the pin modification was as follows: the head of the pin was immersed in the ink and let dry for $15 \mathrm{~min}$ at $70{ }^{\circ} \mathrm{C}$; this procedure was repeated three times and, in the last immersion, the pin was allowed to dry for $12 \mathrm{~h}$. The design of the pin-based electrochemical cell is shown in Figure 1B: the three pins acting as WE (the carbon-ink modified one), RE and CE (both unmodified) were inserted in the transparency sheet taking advantage of the sharp tip of the pins to drill the sheet. For the connection of this device with the potentiostat, a 3-pin Dupont female cable was used.

To perform electrochemical measurements with this device, $70 \mu \mathrm{L}$ of working solution was deposited covering the heads of the three pins.

\subsection{Construction of the Micropipette-Tip Electrochemical Cell}

For the construction of the micropipette-tip electrochemical cell [14], the pins used as WE were modified with carbon ink (50\% of carbon paste in DMF) painting their shaft using a brush. After drying for $15 \mathrm{~min}$ at $70{ }^{\circ} \mathrm{C}$, the painting step was repeated twice more, and after the last one, the pins were left to dry for $1 \mathrm{~h}$ instead $15 \mathrm{~min}$. Then, two unmodified pins (the RE and CE) were inserted in the micropipette tip as indicated in Figure 1C. After this, the desired volume of solution is aspirated 
and the tip was sealed introducing the carbon-ink modified pin (the WE) at the bottom. The connection of this WE to the potentiostat was made through a conductive copper adhesive tape; the $\mathrm{RE}$ and the CE are connected by conventional crocodile clamps.

To perform electrochemical measurements with this device, $360 \mu \mathrm{L}$ of the working solution were aspirated into the tip contacting the three electrodes.
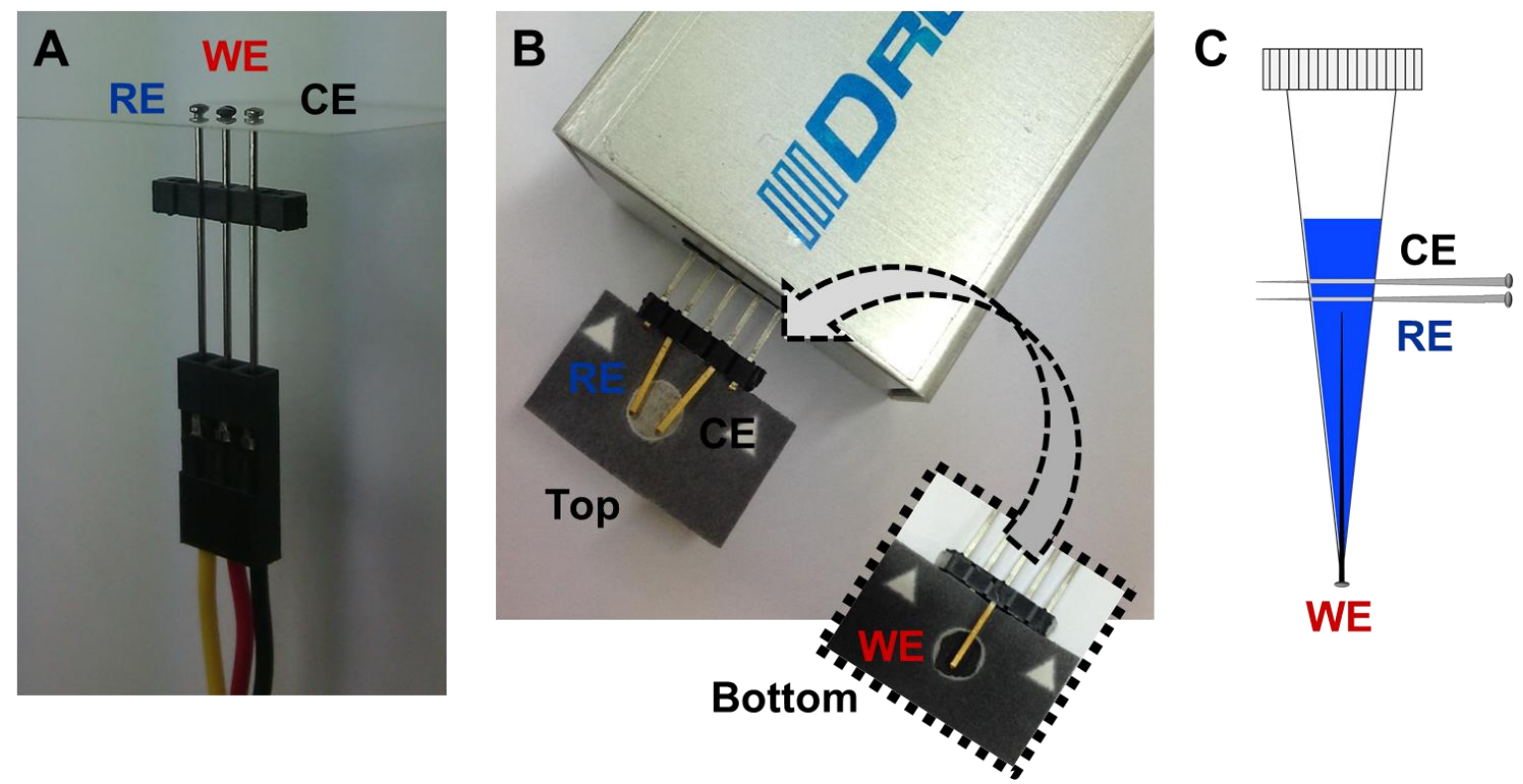

Figure 1. (A) Photograph of the pin-based electrochemical cell combining three stainless-steel pins with a transparency sheet. (B) Photograph of the paper-based cell combining the paper-based WE and the gold-plated pins RE and CE. (C) Schematic representation of the electrochemical cell constructed with a 100-1000 $\mu \mathrm{L}$ micropipette tip and three stainless-steel pins.

\section{Results}

\subsection{Paper-Based Electrochemical Cell}

This electrochemical cell was used to construct an enzymatic sensor for glucose determination [12]. With this aim, the paper-based WE was modified depositing $5 \mu \mathrm{L}$ of a mixture of GOx (1.6 $\left.\mathrm{U} \cdot \mu \mathrm{L}^{-1}\right), \operatorname{HRP}\left(2.5 \mathrm{U} \cdot \mu \mathrm{L}^{-1}\right)$ and potassium ferrocyanide $(0.1 \mathrm{M})$. The analytical signal for glucose concentration was obtained by chronoamperometry (at $-0.1 \mathrm{~V}$ for $100 \mathrm{~s}$ ). In this way, this paper-based sensor was able to quantify glucose in the concentration range comprised between 0.3 and $15 \mathrm{mM}$ with a sensitivity of $-1.19 \mu \mathrm{A} \cdot \mathrm{mM}^{-1}$ and a reproducibility, in terms of relative standard deviation (RSD), of 5.4\%. Moreover, this sensor was applied to the determination of glucose in beverages such as orange juice and cola and the results obtained were compared to those obtained with a spectrophotometric enzymatic kit obtaining very similar results (relative errors lower than $\pm 4 \%$ ).

The high versatility of this platform allowed to construct a multiplexed device (with 8 complete electrochemical cell) and to integrate a sampler that takes the sample without the need of micropipettes [13].

\subsection{Pin-Based Electrochemical Cell}

This pin-based platform was also used as transducer of an enzymatic glucose sensor [7]. The recognition phase of this sensor was prepared in a very similar way as the above mentioned: $3 \mu \mathrm{L}$ of a mixture of GOx $\left(3 \mathrm{U} \cdot \mu \mathrm{L}^{-1}\right), \mathrm{HRP}\left(5 \mathrm{U} \cdot \mu \mathrm{L}^{-1}\right)$ and ferrocyanide $(20 \mathrm{mM})$ were deposited onto the head of the pin acting as WE. In this case, the analytical signal for glucose concentration was obtained by chronoamperometry applying $-0.2 \mathrm{~V}$ for $50 \mathrm{~s}$. The calibration curve obtained covered the range between $0.05 \mathrm{mM}$ and $1 \mathrm{mM}$ with a sensitivity of $1.44 \mu \mathrm{A} \cdot \mathrm{mM}^{-1}$. An RSD value lower than $8 \%$ was 
obtained for this sensor. It was also applied for glucose analysis in honey and orange juice. When the results obtained with the sensor were compared to those obtained with the spectrophotometric enzymatic kit, the high accuracy of this sensor was demonstrated (relative errors lower than $\pm 5 \%$ ).

The versatility of the pins to designs electrochemical cells allowed to construct not only a multiplexed cell with four WE sharing the RE and the CE [7], but also, flow [9] and batch [8] injection analysis systems.

\subsection{Micropipette-Tip Electrochemical Cell}

This micropipette-tip was used to determine SDS in water by the increase that the presence of SDS causes in the cathodic peak of MB, which is related to SDS concentration. In this way, the analytical signal was the current intensity of the cathodic peak obtained when $360 \mu \mathrm{L}$ of a solution containing a fixed concentration of $\mathrm{MB}\left(25 \mu \mathrm{g} \cdot \mathrm{mL}^{-1}\right)$ and SDS (in different concentrations) were aspirated and a linear sweep voltammetry was recorded (from 0.1 to $--0.3 \mathrm{~V}$ at $100 \mathrm{mV} \cdot \mathrm{s}^{-1}$ ). A calibration curve for SDS between 2.5 and $20 \mu \mathrm{g} \cdot \mathrm{mL}^{-1}$ was obtained with a sensitivity of -0.26 $\mu \mathrm{A} \cdot \mathrm{mL} \cdot \mu \mathrm{g}^{-1}$. The reproducibility obtained for this tip-based cell, in terms of RSD, was $7 \%(\mathrm{n}=5)$. The concentration of SDS in spiked tap water was determined obtaining recoveries values of $93 \%-111 \%$.

\section{Conclusions}

The innovative electrochemical cells here described demonstrate the high potential of common and low-cost materials for the development of miniaturized, simple and cheap, but also robust and accurate electroanalytical devices. Moreover, the small size of the presented platforms makes possible their integration with portable instrumentation (potentiostats), obtaining highly useful devices for point-of-need analysis. This is very interesting for a great amount of applications (as clinical diagnosis to environmental analysis) that require decentralized analysis, allowing to take decisions in real time.

Acknowledgments: This work has been supported by the FC-15-GRUPIN14-021 project from the Asturias Regional Government and the CTQ2014- 58826-R project from the Spanish Ministry of Economy and Competitiveness (MINECO, Spain). Andrea González-López thanks the Consejería de Educación y Cultura del Gobierno del Principado de Asturias for the award of her "Severo Ochoa" grant (BP17-36).

\section{References}

1. Ozer, T.; McMahon, C.; Henry, C.S. Advances in Paper-Based Analytical Devices. Annu. Rev. Anal. Chem. 2020, 13, 85-109.

2. Noviana, E.; McCord, C.P.; Clark, K.M.; Jang, I.; Henry, C.S. Electrochemical paper-based devices: Sensing approaches and progress toward practical applications. Lab. Chip. 2020, 20, 9-34.

3. Noviana, E.; Carrão, D.B.; Pratiwi, R.; Henry, C.S. Emerging applications of paper-based analytical devices for drug analysis: A review. Anal. Chim. Acta 2020, 1116, 70-90.

4. Yang, Y.; Noviana, E.; Nguyen, M.P.; Geiss, B.J.; Dandy, D.S.; Henry, C.S. Paper-Based Microfluidic Devices: Emerging Themes and Applications. Anal. Chem. 2017, 89, 71-91.

5. Gong, M.M.; Sinton, D. Turning the Page: Advancing Paper-Based Microfluidics for Broad Diagnostic Application. Chem. Rev. 2017, 117, 8447-8480.

6. Glavan, A.C.; Ainla, A.; Hamedi, M.M.; Fernández-Abedul, M.T.; Whitesides, G.M. Electroanalytical devices with pins and thread. Lab. Chip. 2016, 16, 112-119.

7. Rama, E.C.; Costa-García, A.; Fernández-Abedul, M.T. Pin-based electrochemical glucose sensor with multiplexing possibilities. Biosens. Bioelectron. 2017, 88, 34-40.

8. García-Miranda Ferrari, A.; Amor-Gutiérrez, O.; Costa-Rama, E.; Fernández-Abedul, M.T. Batch injection electroanalysis with stainless-steel pins as electrodes in single and multiplexed configurations. Sens. Actuators B Chem. 2017, 253, 1207-1213.

9. Rama, E.C.; Costa-García, A.; Fernández-Abedul, M.T. Pin-based flow injection electroanalysis. Anal. Chem. 2016, 88, 9958-9963. 
10. Martín-Yerga, D.; Álvarez-Martos, I.; Blanco-López, M.C.; Henry, C.S.; Fernández-Abedul, M.T. Point-ofneed simultaneous electrochemical detection of lead and cadmium using low-cost stencil-printed transparency electrodes. Anal. Chim. Acta 2017, 981, 24-33.

11. Weng, X.; Kang, Y.; Guo, Q.; Peng, B.; Jiang, H. Recent advances in thread-based microfluidics for diagnostic applications. Biosens. Bioelectron. 2019, 132, 171-185.

12. Amor-Gutiérrez, O.; Costa Rama, E.; Costa-García, A.; Fernández-Abedul, M.T. Paper-based maskless enzymatic sensor for glucose determination combining ink and wire electrodes. Biosens. Bioelectron. 2017, 93, 40-45.

13. Amor-Gutiérrez, O.; Costa-Rama, E.; Fernández-Abedul, M.T. Sampling and multiplexing in lab-on-paper bioelectroanalytical devices for glucose determination. Biosens. Bioelectron. 2019, 135, 64-70.

14. González-López, A.; Costa-Rama, E.; Fernández-Abedul, M.T. Electrochemical Micropipette-Tip for LowCost Environmental Applications: Determination of Anionic Surfactants through their Interaction with Methylene Blue. Talanta 2020, 13, 121732.

Publisher's Note: MDPI stays neutral with regard to jurisdictional claims in published maps and institutional affiliations.

(C) 2020 by the authors. Submitted for possible open access publication under the terms and conditions of the Creative Commons Attribution (CC BY) license (http://creativecommons.org/licenses/by/4.0/). 